\title{
FERRAMENTAS E METODOLOGIAS DE PREVENÇÃO À INADIMPLÊNCIA: UM ESTUDO DE CASO
}

\section{ARTIGO ORIGINAL}

MANGILI, Luiz Ricardo ${ }^{1}$

MANGILI, Luiz Ricardo. Ferramentas e metodologias de prevenção à inadimplência: um estudo de caso. Revista Científica Multidisciplinar Núcleo do Conhecimento. Ano 04, Ed. 04, Vol. 06, pp. 132-144. Abril de 2019. ISSN: 2448-0959

\section{RESUMO}

O objetivo deste artigo é comprovar que através de ações preventivas e metodológicas é possível reduzir os riscos dos negócios sem comprometer a comercialização dos bens ou serviços. Foram coletadas informações em uma empresa de varejo, durante os períodos de Janeiro à Abril de 2017 e o mesmo período no ano de 2018, sobre o faturamento e os índices de inadimplência. Implementadas algumas mudanças, como: utilização das ferramentas de proteção ao crédito; análise da capacidade de crédito suportada pela pequena empresa; migração das contas em carteira para a utilização dos cheques e cartões de créditos; treinamentos com equipe do departamento de crédito; elaboração de políticas de crédito, cobrança e a conscientização de consumidores para a análise real do que e para que estão gastando, foram feitos monitoramentos pelo departamento de crédito, através do DRE - Demonstrativo de Resultados do Exercício. Criou-se o hábito de mensalmente medir os volumes de vendas com os valores das contas a receber, para rapidamente promoverem as ações de reduzir os valores em atrasos. Com as ações implementadas, os resultados comparados ficaram claros, positivando a redução da inadimplência, trazendo para o caixa da empresa uma liquidez mais rápida, consolidando o fluxo de caixa mais próximo da realidade da empresa.

\footnotetext{
1 Pós-Graduado Em Marketing E Docência Do Ensino Superior.
} 
Palavras-chave: Inadimplência, Crédito, Cobrança, Liquidez, Caixa.

\section{INTRODUÇÃO}

O objetivo do artigo é comprovar que através de ações preventivas e metodológicas é possível reduzir os riscos dos negócios sem comprometer a comercialização dos bens ou serviços. Com interação de toda equipe, com treinamentos e um dossiê em forma de cartilha, que facilitará e orientará o uso correto das ferramentas propostas.

Prazeres (2008 a) aponta que, é importante focar e explicar como é realizado e concedido o processo de crédito nas empresas. Pode ser um facilitador existente para as vendas. Através do meio de conceder ao cliente um crédito, as empresas conseguem vender muito mais do que venderiam caso não utilizassem o mecanismo facilitador; neste contexto, o crédito. Por outro lado, pode-se considerar o crédito um fator de risco para as empresas; afinal, com isso, as concessões de crédito deverão estar cada vez mais presentes nas relações comerciais, devido sua importância para a prevenção da inadimplência que vem crescendo nas pequenas empresas de varejo. Motivos esses que partem desde a má análise de crédito, até o preenchimento inadequado dos cadastros dos consumidores.

Da Silva (2007) explica que, na análise de crédito a base cadastral bem feita por uma empresa, pode diminuir os riscos de inadimplência, para assim poder assegurar sua rentabilidade, tornando essencial à sua sobrevivência, um cuidado especial nas decisões de concessão de crédito.

Para isso, a redução da inadimplência deverá estar correlacionada à metodologia da prevenção, através da análise de crédito, equipes e departamentos bem treinados e cadastros bem elaborados. Toda essa metodologia e proposta abordada neste artigo devem ser elaboradas em formato de cartilha e serem utilizadas como ferramentas indispensáveis por todos os colaboradores e empresários que queiram manter protegida a saúde financeira de sua empresa (DA SILVA, 2007).

Mesmo percebendo mudanças nos comportamentos de créditos por parte dos agentes financiadores e por uma minoria de consumidores, Blatt (1999) aponta que, 
muitos empresários não se preocupam em analisar a parte creditícia dos consumidores. Este fato gera problemas ao longo do tempo de vida da empresa, como a falta de capital de giro, devido à inadimplência, podendo levar a empresa à falência, portanto, ter a preocupação do prazo prescricional dos títulos, cheques, notas promissórias e contas em atraso é um fator intrínseco para o caso de execuções. Para tanto, devem-se escolher os métodos adequados e preventivos em relação às análises de créditos e as formas de cobrança junto aos inadimplentes, onde se deve levar em conta se esse inadimplente é do tipo que merece voltar a ser cliente ou não.

O objetivo do artigo é comprovar que através dessas ações preventivas que é possível reduzir os riscos dos negócios, pois, segundo Leoni; Leoni (1997) quando se entrega um bem ou serviço mediante uma promessa de pagamento em data futura, se estabelecem uma relação de confiança entre ambas as partes envolvidas no negócio sem comprometer a comercialização dos bens ou serviços

\section{DESENVOLVIMENTO}

A atuação efetiva de análise do crédito passa a ser básica na avaliação do risco e da recuperação de ativos, contribui na criação de novos negócios ou na potencialização dos já existentes. Isso vai ao encontro do conceito moderno de que todos os departamentos de uma empresa devem participar do desenvolvimento e da maximização da lucratividade do negócio.

O artigo foi elaborado através de pesquisa experimental, bibliográfica e documental, com o Demonstrativo Resultado do Exercício (DRE), em uma empresa varejista, no segmento de Auto Mecânica, no interior de São Paulo, na cidade de Barra Bonita SP.

Através da metodologia aplicada, foi promovida uma entrevista com perguntas fechadas, aos clientes e com o empresário do setor varejista. Levantou-se informações sobre a situação financeira da empresa através da ferramenta, DRE Demonstrativo do Resultado no Exercício no ano de 2018, comparado com o ano de 2017; com os colaboradores levantaram-se as questões de prazos estabelecidos para 
vendas, formas de concessão de crédito, ações de cobrança e atendimento aos clientes devedores. Após levantamento, foram propostas algumas mudanças, pois os números de inadimplência se apresentavam elevados demais para o segmento (BLATT, 1999).

Após as ações propostas, tais como pesquisas com os clientes consumidores, treinamentos com os colaboradores do departamento de crédito e cobrança, criando mecanismos e normas de ações efetivas para a prevenção da inadimplência, forma correta de preenchimento de cadastro, instruções na abordagem de clientes inadimplentes, criou-se fluxos de trabalhos com as ligações telefônicas, envios de cartas aos clientes inadimplentes e monitoramento de todas as ações estabelecidas, no intuito de medir a eficiência e os resultados (PRAZERES, 2008).

Ao término das análises, do DRE (demonstrativo dos resultados e exercícios) de 2017 e 2018, ficaram claros os resultados, indicando a redução da inadimplência através dos cuidados apresentados em relação à abertura do crédito e as ações promovidas no departamento de crédito e cobrança.

\section{INADIMPLÊNCIA}

As perdas potenciais do crédito com a inadimplência ocorrerão sempre que as taxas de juros não acompanharem a evolução da inflação e os custos da empresa. Entendase que esse comportamento das taxas de juros influenciaria na qualidade de crédito e, portanto, na redução do retorno efetivo dos clientes nas vendas e prazo. Seria bom se todos os clientes pagassem suas faturas na data do vencimento, mas não é isso que acontece, uma vez que pode acontecer de o cliente adiar o seu pagamento (PRAZERES, 2008 a).

Os consumidores caloteiros representam uma fatia mínima em empresas que adotam uma política organizada de concessão de crédito e, por isso, é um erro muito grave tratar todos os clientes inadimplentes como devedores duvidosos (BLATT, 1999).

Prazeres (2008 a) alerta a equipe de análise e crédito para observar os comportamentos dos inadimplentes, conforme alguns a seguir: 
- Devedor compulsivo: compra por impulso, esquece-se de compromissos já assumidos;

- Devedor negligente: precisa sempre ser lembrado de seus compromissos, não organiza as datas de pagamento;

- Devedor ocasional: sente-se envergonhado pelo fato de estar inadimplente, pois não está acostumado a essa situação;

- Devedor sazonal: é aquele que atua em segmentos que são afetados por sazonalidade;

- Devedor profissional: não se nega a pagar a dívida, mas nunca paga;

- Devedor mau pagador: é o verdadeiro caloteiro. Compra ciente de que não pagará e quando cobrado se recusa a quitar seus débitos.

Segundo Prazeres (2008 a) diz que conceder crédito aos clientes representa assumir custos e riscos que não existem nas vendas a vista, tais como:

- Despesas com análise do potencial de crédito dos clientes;

- Despesas com a cobrança das duplicatas ou cheques;

- Riscos de perdas com os créditos incobráveis;

- Custos dos recursos aplicados nas contas a receber;

- Perda de poder aquisitivo do valor dos créditos em decorrência do processo inflacionário.

Nas empresas dos setores do comércio e de serviços, a inadimplência tem um aumento nos três primeiros meses do ano, em decorrência das vendas efetuadas no mês de dezembro. E é justamente nestes meses iniciais que ocorre a queda nas atividades destes setores empresariais, deixando assim muitos empresários em dificuldades, tendo em vista que contavam com o pagamento das vendas parceladas de final de ano, para suprir o baixo volume de vendas. Neste caso verificamos dois tipos de sazonalidade: a de aumento das vendas, que ocorre no final do ano, quando a maioria das pessoas recebe o $13^{\circ}$ salário, passando assim a consumir mais, sendo que grande parte das compras é feita de forma parcelada, por meio de cheque prédatado, cartões de crédito ou financeiras. (SEBRAE/RJ, 2009) 
O SEBRAE/RJ (2009) informa ainda que, pesquisas mostram que o valor das prestações em atraso se concentra na faixa que vai até $R \$ 200,00$ (duzentos reais), para isso o empresário deverá seguir algumas regras antes de proceder à concessão do crédito ao seu cliente. Uma prática muito usada no mercado é o encurtamento nos prazos de pagamento, isto é, anteriormente o comércio trabalhava com planos de financiamento mais longos, hoje se trabalha com planos de no máximo 03 parcelas.

\section{CONCEITOS E ANÁLISES DE CRÉDITO}

O Crédito consiste no ato de confiar, acreditar. A confiança faz parte do nosso cotidiano, convivemos em sociedade porque acreditamos que outros agirão de acordo com regras ou padrões socialmente estabelecidos, ou seja, quando atravessamos a rua temos a confiança de que o motorista respeitará o sinal. Nas transações de compra e venda, entre consumidores e empresas do comércio de bens e serviços, o crédito segue o princípio de confiança. Quando se entrega um bem ou serviço mediante uma promessa de pagamento em data futura, se estabelecem uma relação de confiança entre ambas as partes envolvidas no negócio (LEONI; LEONI, 1997).

Para Sandroni (2005) crédito é a transação comercial em que um comprador recebe imediatamente um bem ou serviço adquirido, mas só fará o pagamento depois de algum tempo determinado. Essa transação pode também envolver apenas dinheiro. O crédito inclui duas noções fundamentais: confiança, expressa na promessa de pagamento, e tempo entre a aquisição e a liquidação da dívida.

Prazeres (2008 a) destaca que, é importante focar e explicar como é realizado e concedido o processo de crédito nas empresas. Pode ser definido como um facilitador existente para as vendas. Através do meio de conceder ao cliente um crédito, as empresas conseguem vender muito mais do que venderiam caso não utilizassem o mecanismo facilitador, neste contexto; o crédito. Por outro lado, o objetivo da análise de crédito é decidir sobre a possibilidade de conceder ou não o crédito ou empréstimo a um determinado cliente, uma tarefa complexa, na qual se deve tomar uma decisão mediante fatos e, ou informações, às vezes incompletas e incertas. 


\section{CADASTRO}

Da Silva (2007) explica que, na análise de crédito a base cadastral bem feita por uma empresa, pode diminuir os riscos de inadimplência, para assim poder assegurar sua rentabilidade, tornando essencial à sua sobrevivência, um cuidado especial nas decisões de concessão de crédito.

As principais causas da mortalidade das empresas são: comportamento empreendedor pouco desenvolvido; falta de planejamento prévio; gestão deficiente do negócio; insuficiência de políticas de apoio; conjuntura econômica; problemas pessoais dos proprietários; e problemas na administração do crédito e inadimplência, pela falta de comprometimento no preenchimento exato de um cadastro para análise do crédito (SEBRAE, 2009).

Prazeres (2008 a) baseia-se em alguns pilares para o preenchimento de um cadastro para um consumidor:

- Identificar e localizar o cliente: significa que não basta simplesmente escrever o endereço de trabalho e residência. O importante é você sentir que localizou o cliente. Se tiver dúvidas sobre o nome de ruas ou bairros utilize o guia de ruas de sua cidade para fortalecer o preenchimento do cadastro.

- Verificar sua capacidade de pagamento através de sua renda.

-Verificar e comprovar sua experiência de crédito: a experiência de crédito anterior é

Blatt (1999) levanta alguns pontos importantes baseados nos cadastros dos clientes, antes da liberação de sua compra no crediário:

-Levantar todas as informações comerciais;

-O histórico de pagamentos pontuais do cliente, auxilia o analista na aprovação do crediário; 
-Quando solicitar aos clientes as referências comerciais ou bancárias, verificar se o mesmo possui carnês, duplicatas, promissórias, cartões de crédito ou cheques especiais das empresas ou instituições financeiras citadas.

-Caso não sejam apresentadas as referências de crédito, mas apenas citadas as fontes, deve-se desenvolver todo o esforço necessário para obtê-las, pessoalmente ou por telefone.

O mais importante é valorizar o conteúdo da informação. O foco do trabalho está em disponibilizar os dados para a empresa e, além disso, diferenciar seus clientes e manter os relacionamentos de acordo com a sua importância para a empresa.

\section{INFORMAÇÕES DE CRÉDITOS PARA OS CADASTROS}

Consultas às centrais de informações de crédito identificam a existência de dívidas e protestos junto ao comércio, a outras instituições financeiras e a órgãos públicos (DA SILVA, 2007).

Segundo Prazeres (2008 a) a avaliação sobre a concessão de crédito concentra-se em:

a) Fixação de prazo: de quanto tempo disporá o cliente para pagar. O prazo determina a rotação do investimento em contas a pagar e a receber;

b) Fixação de critérios para aceitação de um cliente em potencial: avalia o risco do cliente face ao incremento de vendas e face aos lucros que ele pode proporcionar.

Entre os inúmeros fatores que devem ser analisados na decisão de crédito, dois irão impactar diretamente na administração do capital de giro da empresa: o volume de vendas (sejam à vista ou à prazo) e o prazo de pagamento (BLATT, 1999).

Em termos financeiros, Prazeres (2008 a) aponta três fatores primordiais para a decisão da concessão de crédito: os recebimentos postergados (nas vendas à prazo) com a concessão de crédito; a probabilidade de pagamento e a taxa de retorno exigida para os fluxos de caixa postergados (taxa de juros embutida na venda). 


\section{COBRANÇA}

$\mathrm{Na}$ área de cobrança, a política é de cobrar energicamente os valores vencidos, e reutilizando-se todo o processo de recebimento de duplicatas através de instituições bancárias. Tem como metas receber um montante de dinheiro no mês corrente e reduzir valores de duplicatas vencidas. Num mercado cada vez mais competitivo, em que a qualidade e o preço dos produtos e serviços costumam ser nivelados pela concorrência, o diferencial na área de crédito e cobrança está no talento humano, visto como a chave para maximizar o desempenho e os resultados de uma empresa. Hoje, o acesso às informações para análise de crédito é muito mais ágil. Com um tempo menor de análise, o papel do analista se transforma através do surgimento de oportunidade de novos negócios, alcançando também a prospecção, a potencialização de vendas, a higienização de cadastros e o gerenciamento de carteiras (PRAZERES, 2008 b).

Ao oferecer crédito para pessoas físicas de menor poder aquisitivo, pode-se pressupor que haja certo índice de inadimplência por parte dos mesmos. Nesse momento, entram em cena os cobradores, que podem ser bons ou maus na execução de suas atividades. Há os que fazem uso de práticas abusivas, que pretendem receber o valor a qualquer preço, e há também os que sabem aproveitar bem a situação para receber o valor da dívida e ainda manter um elo de fidelidade com os clientes (PRAZERES, 2008 b).

O cobrador que utilizar meios que exponham seu cliente ao ridículo segundo Blatt (1999), como ameaças, coação, linguagem violenta, constrangimentos, etc., estará sujeito à pena e multa específica. Portanto, para evitar esses dissabores, é importante que o profissional da área de cobrança saiba como lidar com os seus clientes inadimplentes de forma que a cobrança não seja uma situação negativa, um bicho de sete cabeças que, na maioria das vezes, traz grandes prejuízos e aborrecimentos aos clientes.

Desde sua fundação, desta empresa de Mecânica Automotiva, até a transferência de comando, a empresa nunca se preocupou em providenciar uma análise de crédito dos 
clientes, criação de política de crédito, trabalhos preventivos de crédito e até mesmo ações corretivas de cobrança. Diante dessa postura sem as prevenções de crédito e a economia do país sofrendo alterações constantes, a empresa começou a conhecer outro cenário. A empresa passou a enfrentar alguns problemas e se deparar com algumas situações que até antes não preocupava a administração. Altos índices de devoluções de cheques, contas de clientes em grande concentração de atraso, pagamentos efetuados fora do prazo combinado e clientes considerados de potencial atrasando pagamentos.

Leoni e Leoni (1997) dizem que quando se entrega um bem ou serviço mediante uma promessa de pagamento em data futura, se estabelece uma relação de confiança entre ambas as partes envolvidas no negócio; neste caso a empresa confiava, mas o cliente não cumpria com sua parte, na maioria das vezes, por falta de acompanhamento da área administrativa.

Demonstrativo de resultados do exercício (DRE) sem as ações preventivas de crédito e cobrança (2017)

Os valores apresentados, Tabela 1, são reflexos de ações de crédito e cobrança que não eram praticados. Blatt (1999) ressalta a importância sobre cada empresa ao instituir e implantar uma política de crédito, que trabalhe e estude o passado da empresa, avalie os riscos presentes e trace uma política coerente para que no futuro o resultado da lucratividade seja maior que o da perda. 
Tabela 1: Demonstrativo do Resultado do Exercício Jan - Fev - Mar - Abr - 2017.

\begin{tabular}{|c|c|c|c|c|c|c|c|c|}
\hline \multicolumn{2}{|l|}{ Janeiro } & \multicolumn{2}{|c|}{ Fevereiro } & \multicolumn{2}{|c|}{ Março } & \multicolumn{2}{|l|}{ Abril } & \multirow[b]{2}{*}{$\%$} \\
\hline & Valor & $\%$ & Valor & $\%$ & Valor & $\%$ & Valor & \\
\hline Receita Bruta & 34.240 & 100 & 37.984 & 100 & 34.197 & 100 & 32.422 & 100 \\
\hline (-) Impostos & 919 & 2,7 & 801 & 2,1 & 819 & 2,4 & 812 & 2,5 \\
\hline (=) R. Líquida & 33.321 & 97,3 & 37.183 & 97,9 & 33.378 & 97,6 & 31.603 & 97,5 \\
\hline (-) Custo & 21.128 & 91,7 & 19.190 & 50,5 & 18.768 & 54,9 & 14.221 & 43,9 \\
\hline $\begin{array}{l}\text { (=) Margem de } \\
\text { Contribuição }\end{array}$ & 12.193 & 35,6 & 17.993 & 47,4 & 14.610 & 42,7 & 17.382 & 53,6 \\
\hline $\begin{array}{l}(-) \quad \text { Despesas } \\
\text { Fixas }\end{array}$ & 20.868 & 60,9 & 19.934 & 52,5 & 22.341 & 65,3 & 27.551 & 85,0 \\
\hline $\begin{array}{l}(+) \quad \text { Receitas } \\
\text { Financeiras }\end{array}$ & 0 & & 0 & & 45 & 0,10 & 22 & 0,10 \\
\hline $\begin{array}{l}(-) \quad \text { Despesas } \\
\text { Financeiras }\end{array}$ & 706 & 2,10 & 542 & 1,40 & 517 & 1,50 & 600 & 1,90 \\
\hline $\begin{array}{l}(=) \quad \text { Resultado } \\
\text { Operacional }\end{array}$ & -9.381 & $\begin{array}{l}- \\
27,40\end{array}$ & -2.483 & $\begin{array}{l}- \\
6,50\end{array}$ & -8.203 & $\begin{array}{l}- \\
24,0\end{array}$ & $\begin{array}{l}- \\
10.747\end{array}$ & $\begin{array}{l}- \\
33,1\end{array}$ \\
\hline $\begin{array}{l}(-) \quad \text { Custos } \\
\text { Econômicos }\end{array}$ & 3.720 & $-10,9$ & 4.725 & $\begin{array}{l}- \\
12,4\end{array}$ & 4.719 & $\begin{array}{l}- \\
13,8\end{array}$ & 4.719 & $\begin{array}{l}- \\
14,6\end{array}$ \\
\hline $\begin{array}{l}(=) \quad \text { Resultado } \\
\text { Econômico }\end{array}$ & $\begin{array}{l}- \\
13.101\end{array}$ & $-38,3$ & -7.208 & $\begin{array}{l}- \\
19,0\end{array}$ & $\begin{array}{l}- \\
12.922\end{array}$ & $\begin{array}{l}- \\
37,8\end{array}$ & $\begin{array}{l}-15 . \\
466\end{array}$ & $\begin{array}{l}- \\
47,7\end{array}$ \\
\hline
\end{tabular}

Fonte: Dados da pesquisa elaborada pelo autor.

Todo esse novo cenário que se desenhava, conforme Tabela 1, veio abalar a administração da empresa, começando a reestruturar toda sua área de crédito e ações em cobrança; pois nessa ciranda de comercialização os recebimentos precisam andar em dia para honrar os compromissos com fornecedores. Com as oscilações do faturamento, fragilidade do crédito, das ações de cobrança e o despreparo da equipe administrativa a inadimplência começou a ganhar espaço. Nesse momento houve a necessidade de planejar toda a área de crédito e cobrança, criando normas e 
procedimentos, treinamentos com equipe administrativa, criação de formas de pagamentos e análise da política de venda.

Demonstrativo de resultados do exercício (DRE) com as ações preventivas de crédito e cobrança (2018).

Tabela 2: Demonstrativo do Resultado do Exercício Jan - Fev - Mar - Abr - 2018.

\begin{tabular}{|c|c|c|c|c|c|c|c|c|}
\hline \multicolumn{2}{|l|}{ Janeiro } & \multicolumn{2}{|c|}{ Fevereiro } & \multicolumn{2}{|c|}{ Março } & \multicolumn{2}{|l|}{ Abril } & \multirow[b]{2}{*}{$\%$} \\
\hline & Valor & $\%$ & Valor & $\%$ & Valor & $\%$ & Valor & \\
\hline Receita Bruta & 49.957 & 100 & 45.706 & 100 & 55.063 & 100 & 54.945 & 100 \\
\hline (-) Impostos & -1.790 & $-3,6$ & 751 & $-1,6$ & -2797 & $-5,1$ & -2.824 & $-5,4$ \\
\hline (=) R. Líquida & 48.167 & 96,4 & 44.955 & 98,4 & 52.266 & 94,9 & 49.191 & 94,6 \\
\hline (-) Custo & 30.245 & $\begin{array}{l}- \\
60,5\end{array}$ & $\begin{array}{l}- \\
25.309\end{array}$ & $\begin{array}{l}- \\
55,4\end{array}$ & 28.407 & $\begin{array}{l}- \\
51,6\end{array}$ & 32.509 & $\begin{array}{l}- \\
62,5\end{array}$ \\
\hline $\begin{array}{l}(=) \text { Margem de } \\
\text { Contribuição }\end{array}$ & 17.657 & 35,3 & 9.207 & 42,0 & 23.463 & 42,6 & 16.479 & 31,7 \\
\hline (-) Despesas Fixas & 18.458 & $\begin{array}{l}- \\
36,9\end{array}$ & 18.842 & $\begin{array}{l}- \\
41,2\end{array}$ & 18.725 & 34,0 & 16.875 & 32,4 \\
\hline $\begin{array}{l}(+) \quad \text { Receitas } \\
\text { Financeiras }\end{array}$ & 165 & 0,33 & 89 & 0,20 & 101 & 0,20 & 143 & 0,30 \\
\hline $\begin{array}{l}(-) \quad \text { Despesas } \\
\text { Financeiras }\end{array}$ & -405 & $\begin{array}{l}- \\
0,81\end{array}$ & -389 & $\begin{array}{l}- \\
0,85\end{array}$ & -524 & -095 & -602 & $\begin{array}{l}- \\
1,10\end{array}$ \\
\hline $\begin{array}{l}(=) \quad \text { Resultado } \\
\text { Operacional }\end{array}$ & -1041 & $\begin{array}{l}- \\
2,08\end{array}$ & 65 & 0,14 & 4.315 & 7,83 & -855 & $\begin{array}{l}- \\
1,56\end{array}$ \\
\hline $\begin{array}{l}(-) \quad \text { Custos } \\
\text { Econômicos }\end{array}$ & -1.809 & $\begin{array}{l}- \\
3,62\end{array}$ & -1.978 & $\begin{array}{l}- \\
4,32\end{array}$ & -802 & $\begin{array}{l}- \\
1,46\end{array}$ & -1.105 & $\begin{array}{l}- \\
2,01\end{array}$ \\
\hline $\begin{array}{l}(=) \quad \text { Resultado } \\
\text { Econômico }\end{array}$ & -2850 & $\begin{array}{l}- \\
5,70\end{array}$ & -1.913 & $\begin{array}{l}- \\
4,18\end{array}$ & 3.513 & 6,38 & -1.960 & $\begin{array}{l}- \\
3,57\end{array}$ \\
\hline
\end{tabular}

Fonte: Dados da pesquisa elaborada pelo autor. 
Diante dos resultados anteriores apresentados na Tabela 1, com relação à Tabela 2, aos trabalhos realizados no departamento de crédito e cobrança, ficou bastante evidente que a prevenção e a orientação para os funcionários envolvidos, apresentaram um resultado bastante considerável.

A primeira ação trabalhada foi à elaboração de um cadastro repleto de informações, tanto para vendas à prazo como para as vendas à vista. Nas vendas à prazo trabalhou-se a estrutura preventiva mais importante, a realidade da renda do cliente para com o valor empregado em seu consumo; concomitantemente foi elaborado um limite de crédito para cada cliente que consumia a prazo sem nenhuma garantia de pagamento. Segundo Prazeres (2008 b) alguns itens importantes para a composição do cadastro foram utilizados na elaboração do cadastro para os clientes, tais como: não abreviar o nome do cliente, preencher o cadastro completamente, anotar todos os telefones e endereços possíveis para localização do cliente, local de trabalho, estado civil e número dos documentos. Nas compras à vista foi solicitada apenas um número de telefone para contato e endereço residencial, utilizando essa informação para um trabalho de marketing, futuramente. Toda essa regra foi primeiramente estudada e desenhada com a equipe de vendas e os funcionários do crédito e cobrança.

Houve também certo receio de alguns clientes, quando solicitado o telefone e endereço nas compras à vista; nesses casos os clientes que relutavam em passar, a empresa respeitava a atitude dos clientes, porém os que passavam o número do telefone e o endereço foram percebidos pela equipe de vendas que não houve clientes insatisfeitos e nem deixaram de utilizar os serviços da empresa.

A empresa adotou assiduamente as consultas nas instituições de proteção ao crédito, principalmente nas emissões de cheques, a consulta se dirige diretamente ao SERASA.

Com o intuito de não deixar a inadimplência crescer, evitar os calotes e reduzir a inadimplência inerente ao consumo criou-se regras de cobrança efetiva. Diante das informações de Prazeres (2008 b) onde mostra como se deve implantar uma rotina no 
setor de cobrança, a empresa partiu para a construção dessa rotina, que se desenhou da seguinte maneira:

- Entre 5 e 10 dias de atraso, a empresa fará contato por telefone com clientes de primeira compra, ou seja, que são novos e não têm histórico de compra. Se não for possível o contato telefônico, enviar primeiro aviso de vencimento; para clientes de segunda compra em diante, usar o contato telefônico ou o primeiro aviso;

- O segundo contato e aviso serão efetuados através de uma carta com teor um pouco mais intenso, caso o cliente não se manifeste após o primeiro telefonema ou primeiro envio de carta;

- Entre 26 e 30 dias de atraso, telefonar ou enviar carta informando que será registrado no SPC, caso não efetue o pagamento;

- Não havendo contato do cliente para com a empresa após todos esses envios de informativos e cobrança, um funcionário da empresa fará o contato pessoalmente, no âmbito de negociação; não havendo uma manifestação do cliente, a justiça será acionada.

\section{CONSIDERAÇÕES FINAIS}

Através da pesquisa desse artigo e dentro das fundamentações dos autores, ficou evidente que existem formas de amenizar e prevenir o risco de inadimplência nas pequenas empresas varejistas, utilizando as ferramentas e modernizando os métodos de avaliação de crédito sem interferência nas vendas, evitando assim uma possível falência das pequenas empresas. Comprovados os resultados no estudo de caso; comprova-se que a análise das operações, através de metodologias simples e práticas, podem passar a ser a chave para o sucesso da empresa.

Vale ressaltar ainda, a grande e fundamental importância das pequenas e médias empresas se cadastrarem nas instituições de pesquisas de varejo tais como; CDL Câmara Dirigente Lojista, SCPC - Serviço Cadastro Proteção ao Crédito, Consultas de Cheques e SERASA, pois, são esses tipos de instituições que poderão apresentar 
números de queda ou alta de inadimplência e evitar as surpresas econômicas e financeiras.

Foi possível reduzir o tempo gasto e proporcionar maior agilidade na verificação dos títulos a vencer e dos atrasados, devido ao forte treinamento, orientação e política de crédito e sistemática de trabalho aplicada. Outro resultado interessante foi à melhoria da qualidade das informações prestadas aos clientes, através das faturas implantadas, relação de serviços com preços e prazos de pagamentos, emissão de boletos e a busca de parcerias com cartões de créditos e financeiras.

Cita-se também a melhoria para o orçamento do fluxo de caixa, onde se pode obter maior confiança no lançamento das duplicatas a receber com um controle mais apurado do setor de crédito e recebimento.

O pesquisador pode compreender as dificuldades das pequenas empresas varejistas, quanto ao fato de implantarem novidades ou mudanças para adequação de sua realidade ao mercado competitivo, porém, há de entender-se que se faz necessário um bom planejamento, uma boa estrutura, uma boa conversa com os colaboradores, antes de qualquer atitude a ser tomada, principalmente quando se trata do fato de mexer com o principal elemento da economia, o cliente.

\section{REFERÊNCIAS}

BLATT, Adriano. Cobrança por Telefone e Negociação com Inadimplentes. 1. ed. São Paulo: Nobel 1999.

DA SILVA, Rubens Filinto. Chega de Inadimplência - Cobrança e Recuperação de Valores. 1. ed. São Paulo: Pilares, 2007.

LEONI, Geraldo; LEONI, Evandro Geraldo. Cadastro, Crédito e Cobrança. São Paulo: Atlas, 1997.

PRAZERES, Hélvio T. Cury. Análise de Crédito e Cobrança na Pequena Empresa. Parte 1 Viçosa-MG: CPT-Centro de Produções Técnicas, 2008 a, 418p. 
PRAZERES, Hélvio T. Cury. Análise de Crédito e Cobrança na Pequena Empresa. Parte 2 Viçosa-MG: CPT-Centro de Produções Técnicas, 2008 b, 200p.

SEBRAE. Cadastros de Clientes. Disponível em: http://www.sebraesp.com.br/faq/marketing/equipe_tecnicas_vendas/montar_cadastr o_clientes. Acesso em 01 set. 2009.

SEBRAE. Concessão de Crédito a Clientes. Disponível em: http://www.biblioteca.sebrae.com.br/bds/BDS.nsf/35E5ED16CE3F0A9503256F9E00 498E72/\$File/NT000A3882.pdf . Acesso em 28 ago. 2009.

SEBRAE. Inadimplência: Como Evitar e Resolver. Disponível em: http://www.sebraesp.com.br/search/node/inadimpl\%AAncia. Acesso em 17 fev. 2009.

SERASA, Inadimplência das Empresas Inicia 2009 em Alta. Disponível em: http://www.serasa.com.br/empresa/noticias/2009/noticia_0660.htm. Acesso em 06 fev. 2009.

Enviado: Março, 2019

Aprovado: Maio, 2019 